\title{
Sustainability lessons learnt from traditional architecture: a case study of the old city of As-Salt, Jordan
}

\author{
Rana Tawfiq Almatarneh \\ Assistant professor at The School of Architecture and Design Al-Ahliyya Amman University, Amman- Jordan
}

\begin{abstract}
Architecture is the art and science of designing which involves the manipulation of space, materials, program and other elements in order to achieve an end which is aesthetic, functional and sustainable. In the past, when the building envelope was the main element man used to protect himself from a harsh climate, he had to depend on passive energy which involves the use of natural energy sources for environmental, healthy, and economical reasons in our buildings. Traditional architecture, in Jordan, represents a living witness for the suitability of this architecture to the local environment, which incorporated the essence of sustainable architecture.

The current study is aimed at investigating the elements of sustainability within the Jordanian traditional buildings based on the Jordan GBI rating key criteria, including: Energy Efficiency, indoor Environmental Quality, sustainable Site Planning and Management, material and Resources, water Efficiency, and innovation. Various typologies of six historical cases (i.e., Abu Jaber, Mouasher, Sukkar, Khatib, Toukan, and Qaqish buildings) in the old city of As-Salt were selected for this study, from a more comprehensive analysis. Findings of the study indicate uniqueness of the overall traditional As-Salt's architecture parallel with the current issues on sustainability. Furthermore, this As-Salt's traditional architecture is so beneficial as a case study for contemporary design, as a template for not only practices that are environmentally friendly, but also the process of sustainable thought.
\end{abstract}

Keywords: Sustainability, Passive design, Traditional building, Energy efficiency, Al-Salt

\section{Introduction}

Cities are artifacts of information, technological change, economic growth and cultural transformation. Throughout history cities have been very complex products of human activity. Now there is a growing worldwide attention to sustainable development, where the needs of today's generation do not conflict with the abilities of future generations to fulfill their needs (Alshuwaikhat \& Nkwenti, 2002). The term has been propelled in an attempt to find a balance between the human economic, social and environmental activities, as well as satisfying the needs of the present generation without compromising the chances for future generations (Hall, 1998).

The construction industry and its activities are responsible for a substantial amount of climate change and waste emissions. It also has an important role to play in socio-economic development and quality of life.

The need was subsequently identified for an internationally agreed upon agenda for sustainable construction to guide the industry in preparing for and implementing the principles of sustainability and support Agenda 21 and the Habitat Agenda.

The desire to control the indoor environment to the occupant's best wishes resulted in the implementation of mechanical climate control systems. Buildings themselves became completely separated from the (outdoor) environment they were placed in. As Maver (qtd in Looman, 2007) puts it, "one of the most market trends in architecture over the centuries has been that of replacing the functions of the building structure by engineering service systems". As residents increasingly voice their demands for better quality living environments via local Agenda 21 initiatives, and as governments advocate quality and sustainability in design, many architects, engineers and building science researchers have been encouraged worldwide to investigate of sustainable traditional buildings and lessons learnt for new contemporary constructions, so sustainability items of traditional buildings can be considered as effective guides for contemporary constructions without imposing additional cost by optimization of energy consumption.

Traditional architecture despite being categorized as primitive has always been the main source of references in the social, cultural, and sustainable studies by architects and researchers. But learning of the traditional architecture does not mean imitation of the past forms while the logic of traditional forms should be learnt and valuable experiences of the intelligent passive methods in buildings and cities should be investigated.

Traditional building applications can cross borders and continents. Brazilian architect Marcio Kogan added a traditional Arabic flair to his Bahia's House in Salvador, Brazil. In addition to the structure's wide open floor plan, which promotes ventilation, Kogan included Mashrabiya windows in his design; the sophisticated latticework of the projecting oriel window provides shade during Bahia's steamy summers while permitting cool 
air to filter in from the street. Much can be drawn from traditional vernacular architecture that will benefit architects today, in terms of aesthetic value, the local style and the sustainable building materials particularly (Vale B, Vale R., 1991). Regardless of where an architect and home builder is based, our ancestors around the world have provided us with plenty of past examples to build for a more sustainable and comfortable present. As such, this paper addresses two questions:

1. Can contemporary architecture be traditional architecture?

2. What are the sustainability lessons learnt from traditional architecture?

\section{Sustainability and the green building index}

Sustainability is currently the most pressing, complex and challenging agenda facing architects. The ever expanding urban population of the globe has meant that over the last decade it has moved on from being a single concern, focused largely on global warming, to one where much wider issues of the environment and health are at stake. Sustainable development has been defined in many ways, Johnson (1996) define sustainability as being rooted in a spirit of cooperation and commitment to utilize technology in a morally and socially responsible manner so that buildings and cities nurture human spirit and fully respect nature; to create sustainable architecture the architect must holistically mesh the knowledge of the new with that the old so that a built environment that respects culture, environment and history of the inhabitants can be created and preserved. World Commission on Environment and Development (The Brundtland Report, 1987) developed a definition that is widely used, contends that sustainable development on the other hand 'meets the needs of the present without compromising the ability of future generations to meet their own needs' (World Commission, 1987).

Mendler, et.al.(2006) also arrived at similar findings in that nature plays a very crucial role in sustainability; for it is efficient and effective in design producing essentially zero waste. Sustainability must take into account a process that is restorative, regenerative, dynamic and efficient as opposed to energy intensive, resource dependent, extractive and disposable methods. Consistent with Salama (1995), sustainability is envisioned as a state in which all humans, now and in the future can live at a decent level of wellbeing within the limits of what nature can and continue to provide.

Sustainable development could be achieved by architects, engineers, designers, town planners, and manufacturers of building products working cooperatively to produce green buildings that are designed, built, renovated, operated, or reused in an ecological and resource efficient manner. Green Architecture is an approach to architectural design that emphasizes the place of buildings within both local ecosystems and the global environment. Green building is the practice of increasing energy efficiency, while reducing building impact on human health and the environment through better siting, design, construction, operation and maintenance. A similar concept is natural building which tends to focus on the use of natural materials, renewable recourses, and passive solar techniques (Wheeler \& Beatley, 2009).

In Jordan, the Green Building Concept started to gain interest since 2009. That's when the Jordan Architect's Association hosted a core group of dedicated professionals, academics and business people to start working on establishing the Jordan Green Building Council (Jordan GBC). Jordan GBC was registered as a Non-Governmental Organization under the Associations Law no. 51, article 11 on October 13th 2009. It is a profession driven initiative to lead the Jordanian property industry towards becoming more environmentfriendly. From its inception, GBI has received the full support of Jordan's building and property players. It is intended to promote sustainability in the built environment and raise awareness among the different construction industry players and the Public about environmental issues. The rating system will provide opportunity for developers to design and construct green, sustainable buildings that can provide energy savings, water savings, a healthier indoor environment, better connectivity to public transport and the adoption of recycling and greenery for their projects.

\section{Passive design}

In general, passive design means ensuring that the fabric of the building and the spaces within it respond effectively to local climate and site conditions so as to maintain comfort for the occupants with the minimal use of energy.

The most important characteristic of passive solar design is that it relies on the integration of a building's architecture, materials selection and construction methods to reduce heating and cooling loads. It takes into consideration local climate conditions, such as temperature, solar radiation and wind; to create climateresponsive, energy conserving structures that can be powered with renewable energy resources (Brown, 2006). Passive solar design also helps conserve valuable fossil fuel resources and reduces greenhouse gases that contribute to global warming. The most important step in the passive cooling process is to develop an energy efficient building envelope to minimize heat gains and to catch cooling breezes. Depending on the climatic condition, passive solar design of the building envelope might comprise the following concerns: orienting; shading devices; thermally massive building materials; and insulation. Landscape and outdoor spaces also play 
an important role in passive cooling strategies. Vegetation, water ponds and fountains are efficient elements in the cooling techniques.

\section{Traditional Building}

Traditional principles have evolved over a long period of time in virtually all countries of the world. People have developed building techniques excellently adapted to the building materials available and local conditions such as the climate. Autochthonous building is a similar principle used by "simple people" (without a specific education in building) adapting their houses to the immediate natural environment and employing locally available materials in an economically sound and resource-efficient manner. A third variant, vernacular building, can be defined as a building culture adapted to the existing environment and available resources, producing houses with the help of traditional techniques which have a certain purpose and represent values, economic conditions, and the lifestyle of the builders (Oliver, 1997).

\section{Method}

The current study is aimed at investigating the elements of sustainability within the traditional buildings in the old city of As-Salt based on the GBI Jordan rating key criteria, including:

- Energy Efficiency

- Indoor Environmental Quality

- Sustainable Site Planning and Management

- Material and Resources

- Water Efficiency

- Innovation

Six traditional buildings (Abu Jaber, Mouasher, Sukkar, Khatib, Toukan, and Qaqish buildings) in the old city of As-Salt were selected for this study, from a more comprehensive analysis. It is hope the traditional Jordanian architecture may possibly represent one of the model case study as potential reference points for future assimilation.

\section{The importance of As-Salt city}

\section{As-Salt's traditional architecture and urban fabric}

As-Salt city was selected as the study area among other Jordanian cities due to its strategic, geographical, political and cultural position as the most historic town in Jordan. For long periods in history it was the most important settlement between the Jordan River and the desert to the east. Because of its history as an important trading link between the Eastern Desert and the west, it was a significant place for the region's many rulers. Moreover, it was once the capital of Jordan.

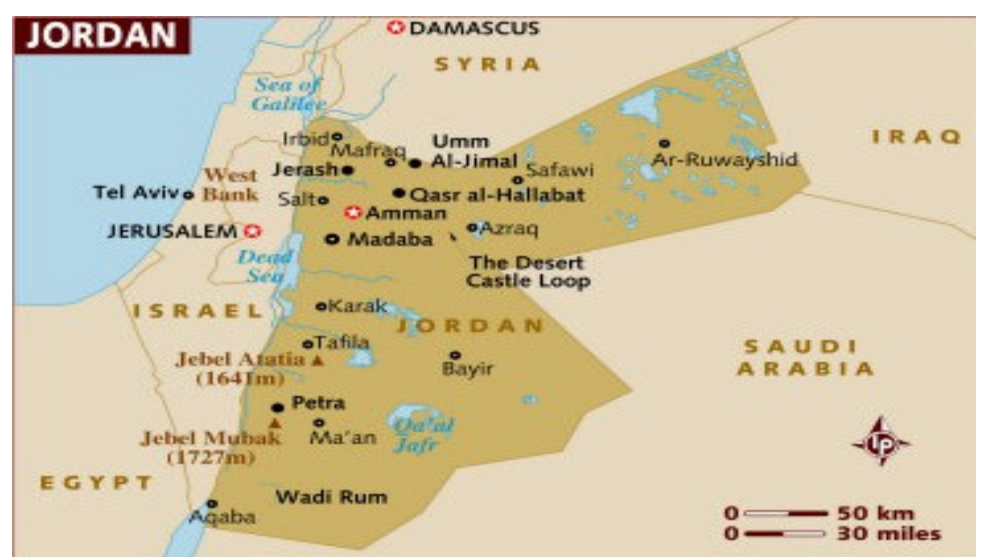

Fig. 1 The map of Jordan- As-Salt. Source: Greater Salt Municipality (2005)

\section{Geography and climate of As-Salt}

As-Salt lies north-east of Amman; situated in the Balqa highland, about 790-1100 metres above sea level, the town is built in the crook of three hills, close to the Jordan River valley. With a population of around 110,000 inhabitants (Jordan Census, 2004) and comprises 80 square kilometres (fig. 1). 

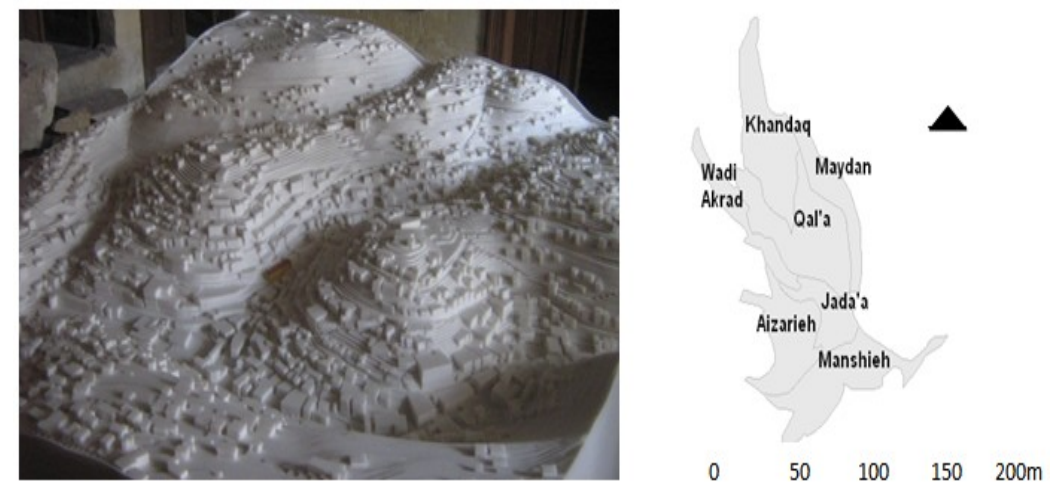

Fig. 2 The old As-Salt modeling (left). Source: Rana Matarneh, 2013. The map of Old As-Salt (right). Source: Greater Salt Municipality (2005)

As-Salt is very well-known with its very steeply geographical terrain. The old city of As-Salt developed around the spring in the Akrad valley (Wadi in the Arabic language), on three hills -including AlQal'a, Al-Jada'a and As-Salalem (fig. 2) - tightly built in clusters of splendid golden houses and buildings, which were built in the yellow limestone of the area. As-Salt climatic zone has a Mediterranean-style; the major characteristic of As-Salt's climate is the contrast between hot, dry, uniform summers and cool, variable winters.

\section{Analysis of indigenous architecture of the old city of As-Salt}

In pre-modern times, people had no choice but to live in harmony with nature. Natural forces were too powerful for available technologies to tame or keep at bay. In this context, the traditional design of Jordan has always been able to effectively respond to its natural environment. This following analysis show us how energy efficiency of traditional buildings greatly and easily achieved at little cost, and in a manner that did not negatively affect lifestyles. As such, the selected cases have been analyzed in terms of energy efficiency, and as essential aspects related to traditional As-Salt architectural practice.
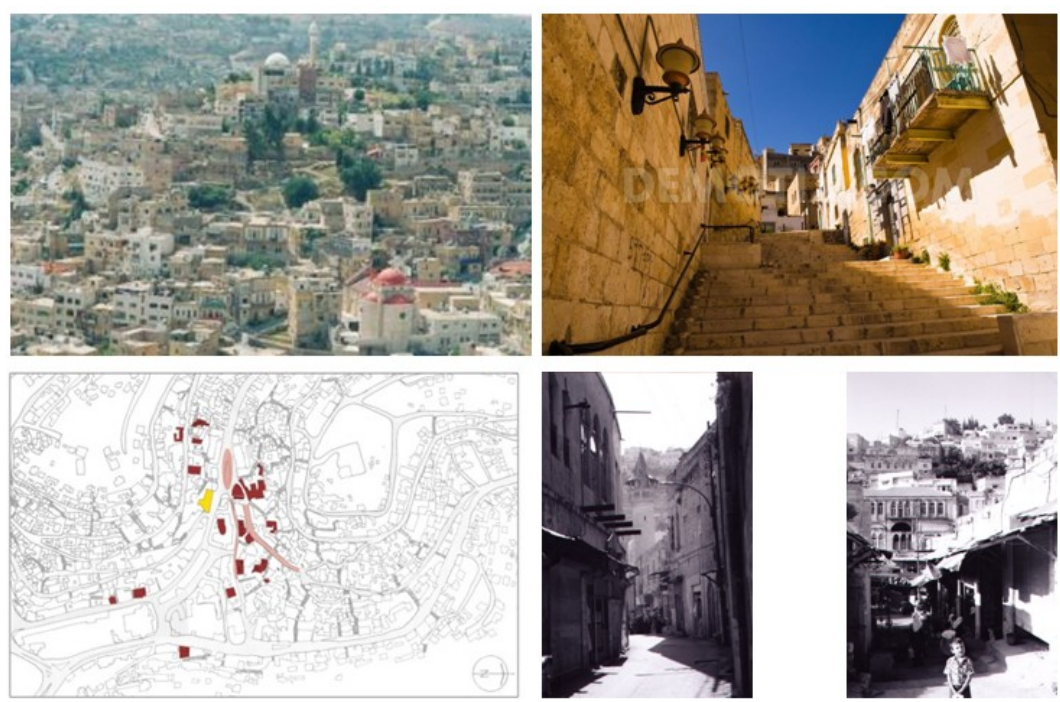

Figure 3-a As-Salt on steep hills, b. with its narrow winding stairways and scenic viewpoints. Source: http://www.demotix.com

\subsection{As-Salt's site planning and urban fabric}

As-Salt is very well-known with its very steeply geographical terrain (fig. 3 left). It is composed of a web of narrow winding footpaths and stone stairways running across the slopes and limited number of roads following the slopes where the contours allowed (fig. 3 right). The narrow streets often found in such traditional cities provide sensitive climatic solutions since they limit the penetration of the hot summer sun into the space of the street, and allow the street to remain in shade during much of the day. Those narrow roads also accelerate air flow, and those same pathways cut at sudden angles to protect pedestrians from the searing summer heat. 


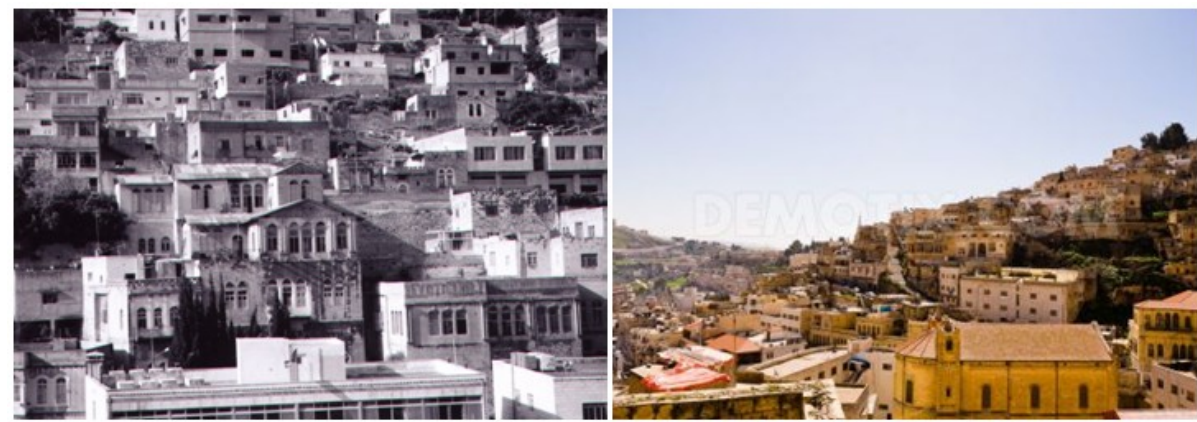

Fig. 4 Compact urban fabric of old city of As- Salt; connected buildings function together as one unit in terms of climate control. Source: Rami Daher (left); http://www.demotix.com (right)

Urban fabrics affect the degree to which buildings may achieve energy efficiency. Obviously, the more it is possible to physically connect buildings, the better those buildings are able to function together as one unit in terms of climate control. Under such_circumstances, each building would provide the adjacent building with additional protection (Mortada, 2003). Accordingly, the compact urban of old city of As-Salt where buildings' clusters overlook each other, where there are often no setbacks from one plot to the other, and no exposed façades except for those facing adjacent streets, is a good example of buildings functioning together as elements of climate control (fig. 4). Moreover, buildings typologies can be ranked by a parameter called "compactness" which is defined as the ratio of the building volume to its exterior wall area. The higher compactness contributes to lower heating and cooling energy demand and consequently the higher energy efficiency. Accordingly, AsSalt traditional buildings typologies can be considered as compact one which is very effective in term of energy efficiency and as an intelligent passive element.

However, urban arrangements in modern cities in Jordan, with their dispersed buildings (often glazed high-rises) and wide streets, are climatically inappropriate. The cumulative effect of these changes is so farreaching as to make poverty itself a major global scourge. Thus, we can see how our ancestors in As-Salt were very aware in using such urban design elements in a very sophisticated and environmental way.

\subsection{Traditional buildings' Design and indoor environmental qualities}

\subsubsection{Typology, orientation and spatial organization}

Building form, plan layout, and orientation contribute to the creation of climatically sensitive buildings. The arrangement of building components around courtyards is a common plan layout of traditional buildings in Islamic regions and Jordanian traditional cities is no exception (fig. 5). It has been noticed that most buildings were oriented towards the south and extended along east-west direction in order to benefit from passive heating supplied by solar radiation. The overall area of openings on the south façade was the largest portion of total area on exterior walls while it was minimized on the northern facades in order to reduce heating energy demand in the building. Orientation has been considered by builders in all six cases in the old city of As-Salt. Moreover, house is oriented toward the southeast direction causing a reduction in solar gains during winter and difficulties with control the solar radiations by shading in summer.

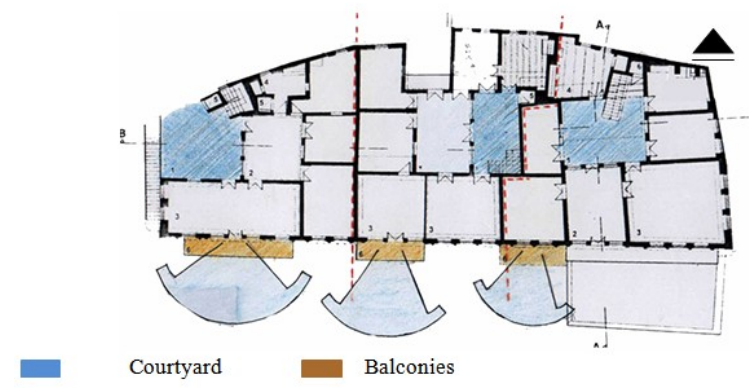

Fig. 5 Typology of traditional building in As-Salt; Abu Jaber house first floor plan with multiple courts open to the sky. Source: Author 2013 


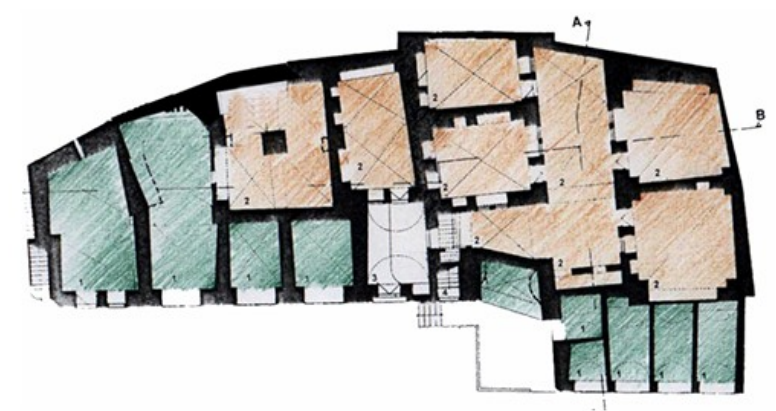

Shops Storages

Fig. 6 Abu Jaber house basement floor multi-use plan: it accommodated both commercial and residential functions as well. Source: Author 2013

As-Salt builders had created building plans that maximize air flow, mitigate their impact on the local environment and offer comfort to residents. Thick walls with athickness from 60 to $100 \mathrm{~cm}$ that block high temperatures and inward window were designed to keep interiors cool and to protect residents from intense heat. Balconies with movable louvers are another feature that allows air to circulate freely. Some of As-Salt traditional buildings had planned to accommodate more than one function. Abu Jaber house is a good example here since it had mixed-used functions. As figure 6 shows, the basement floor of this building had commercial shops with vaulted roofs that leading to As-Salt's main streets and Al Dair street. In the back of the building are the services (storages) (fig.6). However, the first and second floors accommodated a residential function (fig.7).
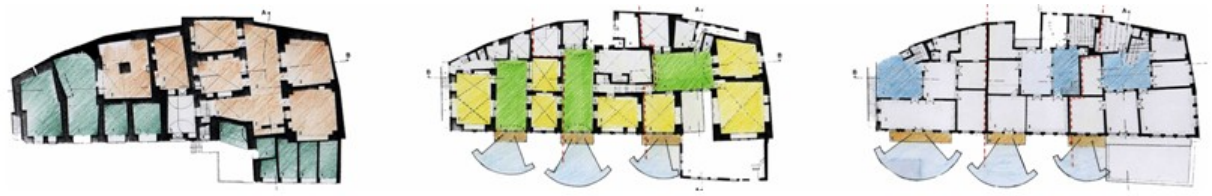
a- Basement floor- shops and storages b-first floor living spaces for the extended family c- second floor bed rooms
Fig. 7 Abu Jaber house basement, first, and second floors. Source: $\underline{\text { Author } 2013}$

\subsubsection{Courtyards}

Courtyard is another environmental element used in As-Salt's traditional buildings. It was integrated into the buildings' design as one of the significant parts of the passive cooling systems. Its features have been designed based on not only climatic factors but also renewable energies and courtyard as one of these determining and organizing factors involves varies aspects. In As-Salt's traditional architecture there were mainly five types of courts; the first type is the court that is in the middle of the building, in which the building is surrounding a court open to the sky (fig. 8-a). Then, there is a court surrounded by semi-covered spaces or galleries (fig. 8- b). In some cases the court is not fully surrounded by the building but by additional fence walls that separate the building and the court from outside (fig. 8-c).
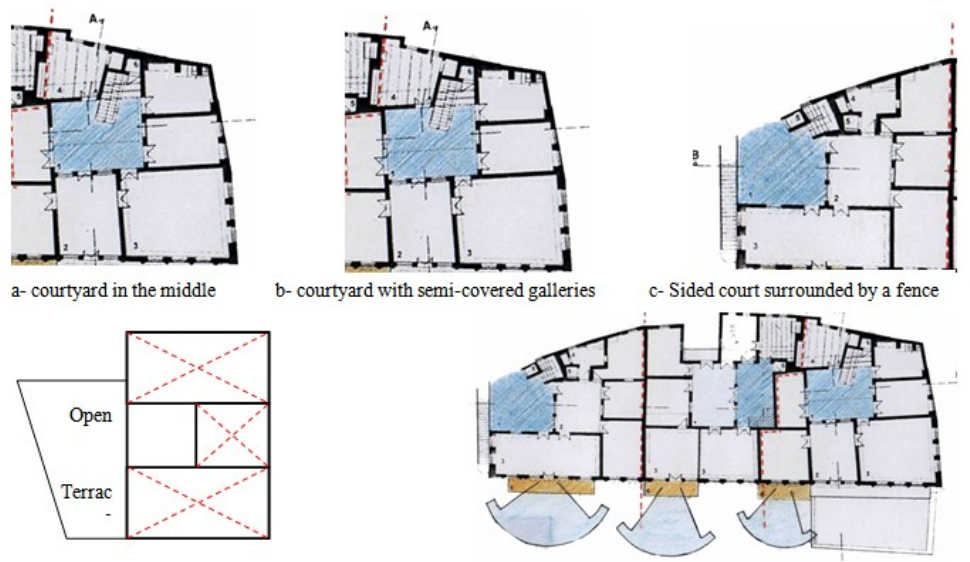

d- Upper courtyard-Open Terrace

e- multi-courtyards in one building

Fig. 8 Courtyards typologies used in As-salt's traditional buildings. Source: Author 2013 
The fourth type is the court that had been created in the upper level as an open terrace (fig. 8-d). And the last type is the multiple courts; each court had its own accessibility and entries or exits from and to the street that the building is exited on (fig. 8-e).

It should be noted that the size of the courtyard is essential to achieve an optimum level of both cooling and heating efficiency, which is important in hot arid climates with hot summers and cold winters. Courtyards used in As-salt's traditional buildings were large with perfect proportions to offer adequate shading in summer and allow sufficient solar radiation gains during winter. They functioned as a microclimate to provide an improved climate inside compared to outside environment. A north cold courtyard and a south warm courtyard were designed in order to provide thermal comfort in the buildings by means of evaporative cooling and cross ventilation. The cold courtyard considered to be shaded in most of the daytime creating natural cooling by the flow of cool air from the courtyard into the building during summer along west side of the site would hinder noise from the street and solar radiation in warm seasons (fig. 8-c).

\subsubsection{Openings}

As-Salt's traditional architecture subsists in hot- arid summer climate and this essential fact governs the shapes, designs, and ornamentations used in the As-Salt's buildings. Open spaces, high ceilings or vaulted or domed roofs, tall arched with clear story windows, and interior courtyards are used to provide good ventilation and airy space (fig. 9).
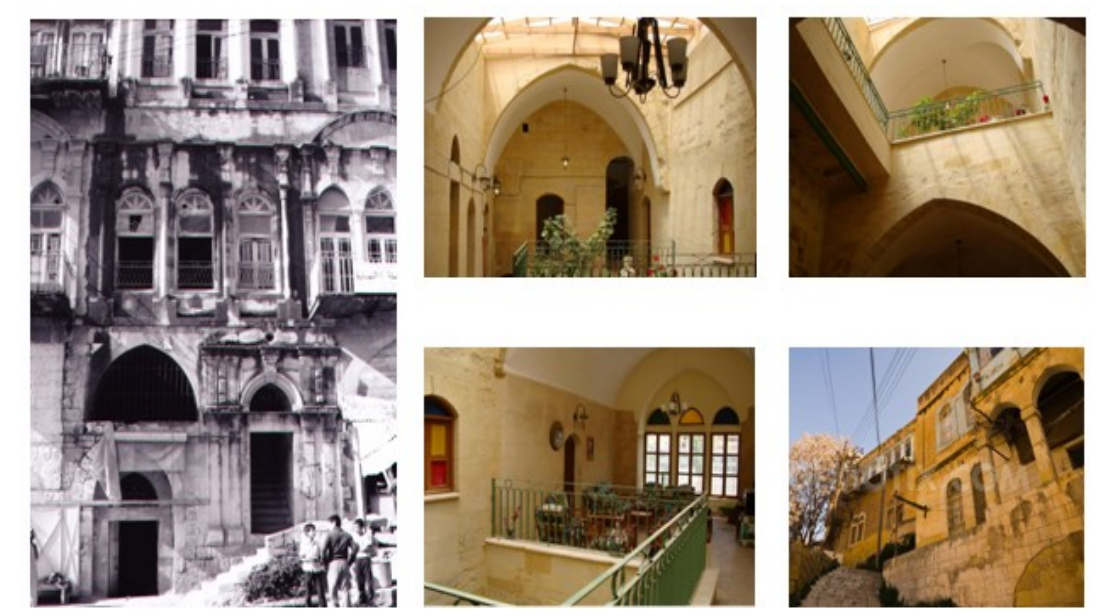

Fig. 9 Multiple tall-arched with clear story windows (left); high ceilings, Balconies, and interior courtyards provide excellent natural ventilation (middle). Source: http://www.demotix.com

Traditionally Mashrabiyyas, grilled wooden window screens, have been used to control the entry of the sun, and there are many examples of them around the traditional architecture in Jordan and As-Salt is no exception. It is worth mentioning here that in traditional architecture, careful attention is paid to the location and size of windows in order to regulate the circulation of air through buildings and the entry of sun. This is evident in the placement of openings in the walls bordering courtyards, in allowing for cross ventilation and in the use of high-level windows to let the hot air out. Also, Shukhshaikhas (clerestory windows) were commonly used as wind and breeze regulators, as in many of As-Salt's traditional houses. If we can apply such a way in our times, the need for energy-devouring air conditioners is eliminated.

\subsubsection{Domed and vaulted roofs}

In As-Salt's traditional architecture, domes and vaults have been widely used to cover buildings' roofs. The barrel vault is a relatively simple example of the vaulted ceiling. It consists of a series of arches arranged in parallel to create a form similar to a half cylinder. The barrel vault is evident in most traditional As-Salt architecture and is a relatively simple form to build, structurally, using the same principles as an archway spread over a broader area. A barrel vault usually adds character to a space. It works especially well for long, narrow spaces (See Figure 10).Vaults have been proved as useful elements in natural lighting, ventilation and passive cooling. Under the vaulted roof, the warm air flow occurs through the openings positioned on the far sides of the vault (See Figure 11). Dominated wind direction during the warm hours of the day is a key factor in designing vaults. In other words, wind blows into the building through the opening facing the wind direction and consequently the internal warm air, which accumulated bellow the roof leaves out from the openings on the opposite side of the vault. 


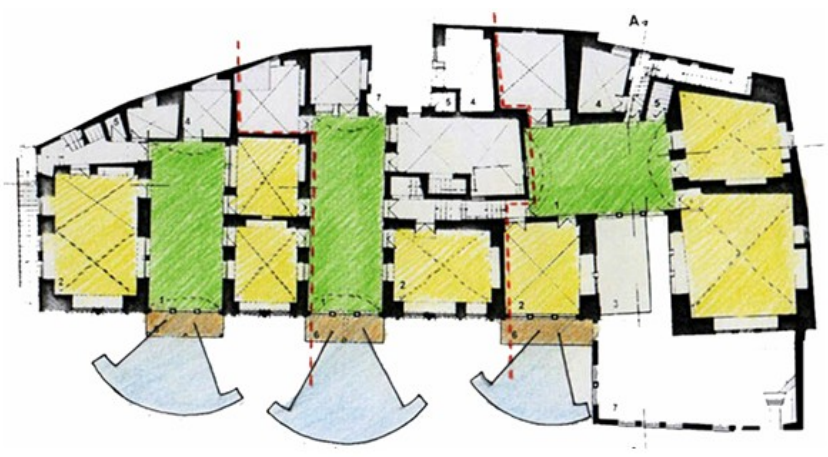

Barrel vaulted galleries cross vaulted rooms

Fig. 10 Abu Jaber house plan- three main barrel vaulted gallery leading to other cross vaulted rooms. Source: Author 2013
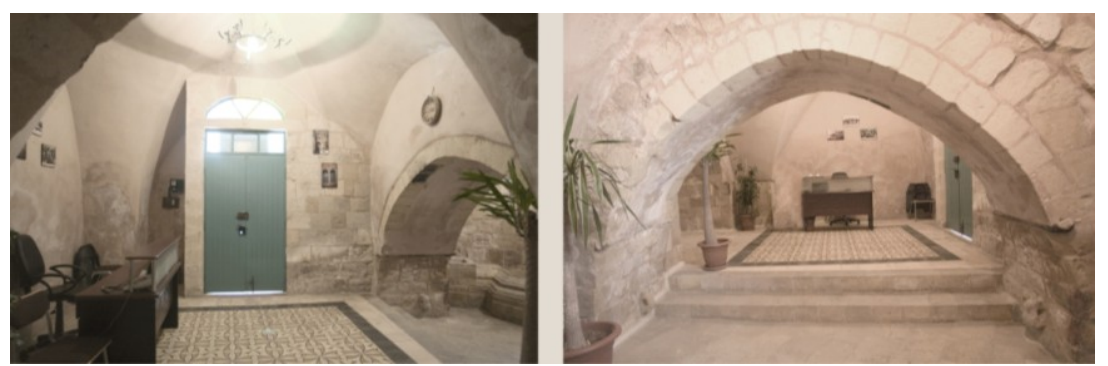

Fig. 11 Madafat Farah Abu Jaber one main barrel vaulted gallery leading to other cross vaulted rooms. Source: Author 2013

\subsection{Building materials and construction methods}

A second track in achieving energy-efficient, climatically interactive design involves the use of appropriate materials for buildings, including walls and roofs. For example, the use of high thermal capacity materials for walls and roofs provides thermal masses that regulate the temperature within structures (See Fig. 10 \&11). Most of traditional buildings in As-Salt used natural materials which are generally lower in embodied energy and toxicity than man-made materials. They require less processing and are less damaging to the environment. Many, like wood, are theoretically renewable. When natural materials are incorporated into building products, the products become more sustainable. Furthermore, using locally produced building materials shortens transport distances, thus reducing air pollution produced by vehicles. Thus, local materials are better suited to climatic conditions, and these purchases support area economies.

\section{Thermal mass and insulation}

Thermal mass is a term used to describe materials of high thermal capacitance i.e. materials which can absorb and store large quantities of heat. Thermal mass may be in the form of masonry walls, roofs, floors, or possibly embedded phase change material. According to local records, in most of the traditional Jordanian villages and cities, walls were built in a typical way. Thick walls used to have a thickness that varies from 80 $120 \mathrm{~cm}$, not only to support the weight of the roof, but also to support the thrust of the vault, and the lateral loads. Traditional houses owing to their very thick walls remained cooler in the summer and warmer in the winter. Utilizing massive walls with high thermal capacity was a suitable solution to reduce the energy demand and improve thermal comfort in buildings especially in hot-arid climates due to wide range of temperature variations during days and nights. The core of the wall, the gap between the outer and the inner courses, is made of small rubble stones, and mortars. Lime, mud and gypsum were the traditional binders used by masons, for centuries in As-Salt, to insulate buildings.

Until the second half of the 20th century, buildings in As-Salt were constructed of numerous natural materials available aplenty in its geographical terrain. Mud, straw, adobe and stone walls have served as thermal masses by limiting the penetration of heat from the sun during the daytime, and returning this heat to the outside during the night. Furthermore, those building materials which had a high thermal capacitance were capable to provide a 'flywheel' effect, smoothing out the variation in temperature within the building, and reducing the swing in temperature on a diurnal and (potentially) longer term basis. As such, local materials were applicable choices for a good solution to control solar radiations in order to achieve energy efficiency objectives. Thus, walls' materials, thickness and construction techniques have presented the best performance in terms of energy sustainability. 


\section{Plaster and Lime washing}

Plaster is the final touch in the building process, in most of the traditional buildings in As-Salt, plaster were used in order to protect the bond stone and to reduce the temperature inside the building. The traditional plaster was made of lime mixed with flax-threads cut in small pieces, brick-dust, sand and ashes. Lime washing or whitewash was part decorating and protecting the plaster; and to let the building breathing and keep it cool in summer and warm in wintertime.

\section{Application for traditional building principles}

\section{Findings and discussion}

The elements of traditional building and its varieties prove that this kind of building is relatively sustainable per se because it adapts to the environment and, furthermore, uses as few resources as possible. It may also usefully add to modern building principles by integrating old building materials like clay into new homes or consistently orienting construction on existing climatic conditions such as solar radiation. Adapting to local conditions and locational requirements (topography, climate, other environmental conditions, social aspects), traditional building offers a number of advantages include:

- the utilization of natural building materials, relatively low energy content of building material, excellent energy-efficiency during the phase of use,

- natural thermal insulation (cold and heat) through appropriate orientation of the building, utilization of thermal masses, integration of shading elements, utilization of the cooling effects of water expanses, compactness of buildings, bright colors of facades, intelligent inner structure, consideration of heat bridges, etc.,

- regional building materials, relatively high share of handwork positively affecting the local labor market, generally user-friendly and easy-to-use materials, adaptation to most adverse conditions, and value enhancement of the building. This shows the superiority of traditional building when applied intelligently.

Table 1.GREEN BUILDING INDEX

Assessment Criteria \& Comments for Traditional Buildings in the Old City of As-Salt

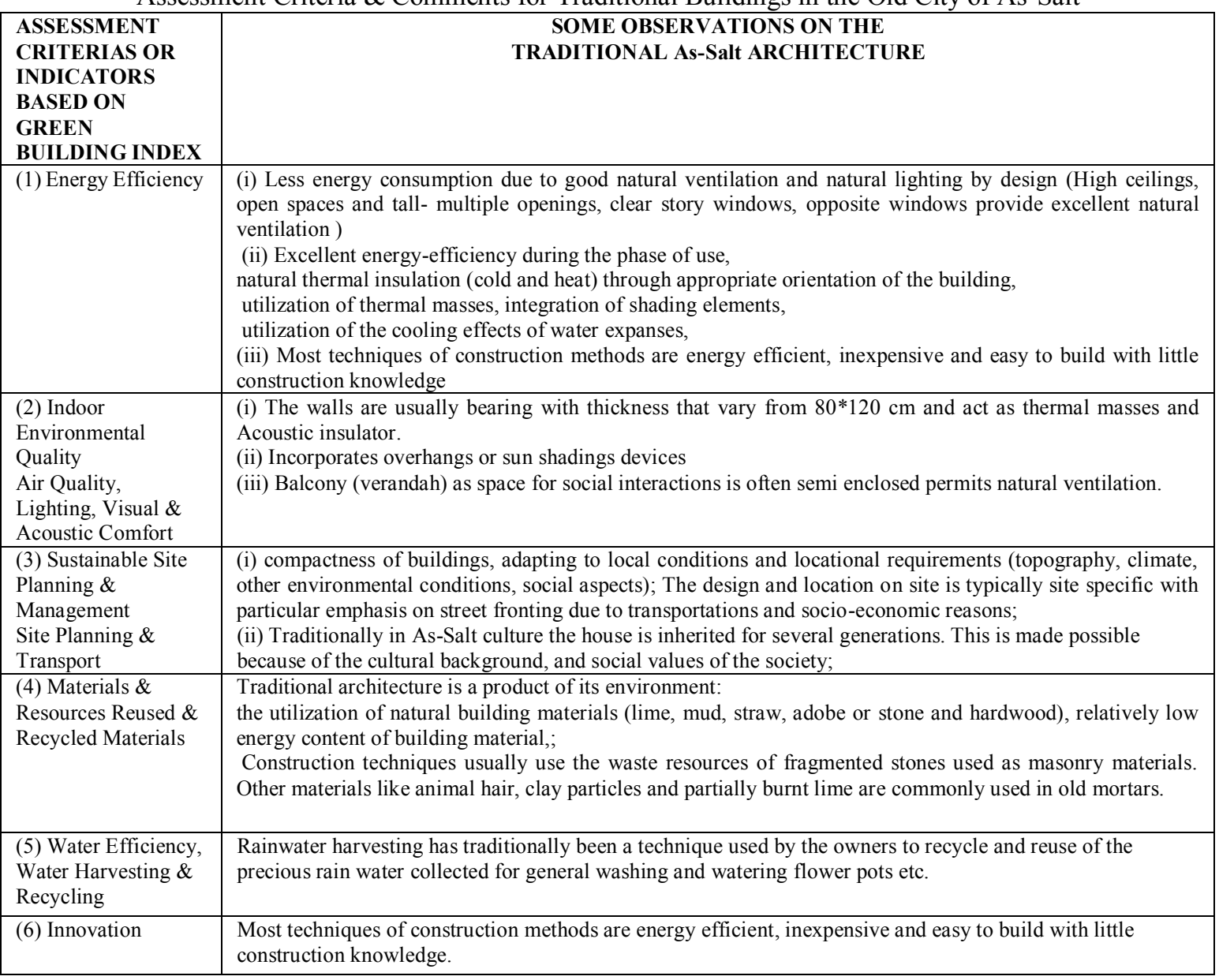




\section{Conclusion}

The overall construction process of the old city of As-Salt city reflects a clear manifestation in the way of life and understanding of the As-Salt's people themselves in relation to man and the natural environment. The sensitivity of the people there towards the natural environment highlights the fact that their mental, physical and emotional needs can co-exist harmoniously in their daily lives. It is worth noting that all the traditional elements in As-Salt architecture are not merely objects of beauty but also as means to create an environment of peace and tranquillity; and this uniqueness can be clearly observed in the functions and meanings of this city's culture and practices. What dictates traditional architecture is not necessarily what is built but how it is built and how that design and build has withstood the test of time and been carried through in other building throughout the community. This study proves that forms of As-Salt's traditional architecture hold the secret to simple, sustainable design. Its architectural elements do play an important role in disseminating the symbolic meanings of its art, design, building materials, and construction methods. Thus, the ecological credentials of As-Salt's premodern building tradition already seem excellent. To the traditional As-Salt, sustainability was a necessity and 'a way of life'; not just a concept. This concept is what makes traditional As-Salt architecture so beneficial as a case study for contemporary design, as a template for not only practices that are environmentally friendly, but also the process of sustainable thought. Finally, in learning from folk architects, we should go beyond the geometrical and physical calculations, notions of forms and symbols, but focus our concerns on the harmonious relationship between man and land, as well as the issues of environmental protection and sustainable development. Traditional architecture elements can be integrated in new buildings with the aim of improving energy efficiency. Architects and designers shall understand traditional elements of design and techniques of construction to function them in their projects without reinventing construction methods.

\begin{tabular}{|c|c|c|}
\hline \multicolumn{3}{|c|}{$\begin{array}{l}\text { Appendix: } \\
\text { List of Figures }\end{array}$} \\
\hline Figure Number & Figure & Page \\
\hline 1 & The map of Jordan- As-Salt & 5 \\
\hline 2 & The old As-Salt modeling;, The map of Old Salt & 5 \\
\hline 3 & As-Salt on steep hills, with its narrow winding stairways and scenic viewpoints. & 7 \\
\hline 4 & Compact urban fabric of old city of As-Salt. & 8 \\
\hline 5 & $\begin{array}{l}\text { As-Salt's traditional buildings- environmental qualities: interior courtyards, and inward } \\
\text { openings }\end{array}$ & 9 \\
\hline 6 & Abu Jaber House- basement floor level & 9 \\
\hline 7 & Courtyards typologies & 10 \\
\hline 8 & Abu Jaber House- basement floor level & 10 \\
\hline 9 & Multiple tall arched openings, clear story windows & 11 \\
\hline 10 & Barrel and cross vaults & 12 \\
\hline 11 & Madafat Farah Abu Jaber & 12 \\
\hline $\begin{array}{c}\text { Table Numbe } \\
1\end{array}$ & $\begin{array}{c}\text { Table } \\
\text { GREEN BUILDING INDEX } \\
\text { Assessment Criteria \& Comments for Traditional Buildings in the Old City } \\
\text { of As-Salt }\end{array}$ & $\begin{array}{l}\text { Page } \\
13-14\end{array}$ \\
\hline
\end{tabular}

\section{References}

[1]. Alshuwaikhat, M. H. \& Nkwenti, I. D. (2002). Developing sustainable cities in arid regions. Cities, 19 (2), 85 -94.

[2]. Brown, G. and M. Dekay, 2006, Sun, Wind, and Light: Architectural Design Strategies, Wiley, London.

[3]. Brundtland, G.H., 1987, Our Common Future, World Commission on Environment and Development (WCED), Oxford University Press, N.Y. pp.4.

[4]. Gaber, T. (2009). Passive systems: Vernacular and contemporary techniques for a vision of sustainable architecture. Egypt: Arch. Cairo,5th International Conference.

[5]. Jordan Green building council, http://www.jordangbc.org/index.php/19-sample-data-articles/joomla/24-joomla

[6]. Hall, P. H (2002). Cities in civilization. London: Weiddenfeld \& Nicolson.

[7]. Johnson, L.E., 1995 Sustainability: Towards an Holistic Vision of Architecture,The Structurist, no.35-36, pp86-98.

[8]. Jordan - Population and Housing Census 2004 - IPUMS Subset. microdata. worldbank.org/index.php/catalog/505

[9]. Looman, R. (2007). Design strategy for the integration of climate-responsive building elements in dwellings. South Africa: CIB World Building Congress.

[10]. Mendler, S., et.al., (2006) The HOK Guidebook to Sustainable Design, 2nd Ed., John Wiley and Sons, Inc., New Jersey.

[11]. Mortada, H. (2003). Traditional Islamic principles of built environment. London: Routledge Curzon.

[12]. Oliver, P. (1997), Encyclopedia of vernacular architecture of the world, Cambridge University Press, Cambridge.

[13]. Royal Scientific Society - Building Research Center, 1990, Architectural heritage in the Hashemite Kingdom of Jordan - Salt. The Ministry of Culture. Amman, Jordan 2011.

[14]. Salama, A., 1995, New Trends in Architectural Education - Designing the Design Studio, Tailored Text \& Unlimited Potential Publishing, U.S.

[15]. Wheeler, S. \& Beatley, T. (2009). The sustainable urban development reader. New York: John Routledge.

[16]. Vale B, Vale R. Green architecture: design for a sustainable future [M]. London: Thames and Hudson Ltd, 1991. 